I. AMS TECHNIQUES 


\title{
Radiocarbon
}

\author{
1986
}

\section{A REVIEW OF THE OPERATION OF THE OXFORD RADIOCARBON ACCELERATOR UNIT}

R J BATTEN, C R BRONK, RICHARD GILLESPIE*, $\mathrm{J}$ A J GOWLETT, R E M HEDGES, and COLIN PERRY

Research Laboratory for Archaeology and the History of Art, Oxford University, 6 Keble Road, Oxford OX1 3QJ, England

ABSTRACT. We describe here the general operation of the Oxford Radiocarbon Accelerator Laboratory which has now been dating routinely for 18 months.

PERFORMANCE AND RESULTS

Sample Size

Our preferred sample size is $5 \mathrm{mg}$ carbon, largely determined by convenient sample chemistry. Ca 10 to $20 \%$ of samples produce between 1 to 5 mg carbon, and these can usually be dated equally satisfactorily. We have produced dates, with counting statistics of ca 3 to $5 \%$, from as little as 100 $\mu \mathrm{g}$ when deposited as a graphite target, but the chemical efficiency is low for such small samples. Samples larger than optimum have the advantage, of course, that extra material is available for a second date, eg, on a different fraction.

Sample Type

The laboratory is set up mainly for archaeologic dating, although support and interest in strictly environmental material is increasing. Figure 1 shows the distribution of the types of material dated, and Figure 2, a histogram of the age range of the dates measured. It excludes a substantial number of dates made on sediment samples as part of research for a D Phil thesis.

There are good archaeologic reasons for preferring bone dates to most other material; it is stratigraphically more secure, often more relevant, and contains organics that can be well characterized chemically. Loss of collagen is not important for most European sites. Many bones from drier, hotter sites contain $<1 \%$ collagen and dating is not attempted on these. Burned bone, on the other hand, generally contains a range of carbonaceous material from alkali-extractable to apparent carbon, and can often be dated when it is not possible to date unburned bone.

Dating of sediment and different fractions are discussed in other papers in this issue (see Batten et al; Fowler, Gillespie \& Hedges; Gillespie, Hedges \& Humm, 1986). Carbonate dating has recently been undertaken

* Department of Geosciences, University of Arizona, Tucson 

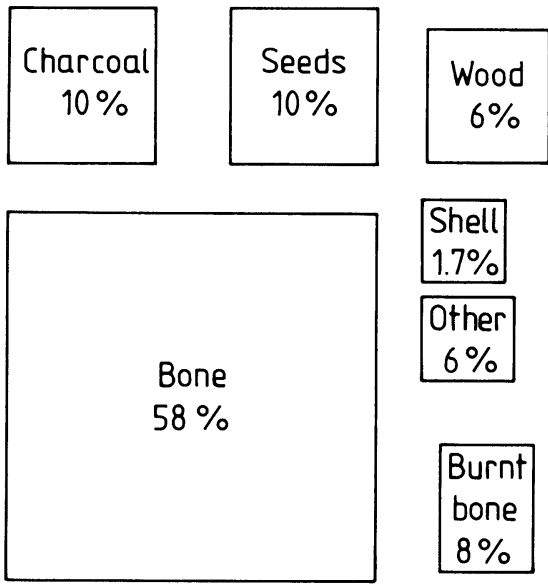
tory

Fig 1. Archaeologic material measured by the Oxford Radiocarbon Accelerator Labora-

Histogram of dates from archaeological samples

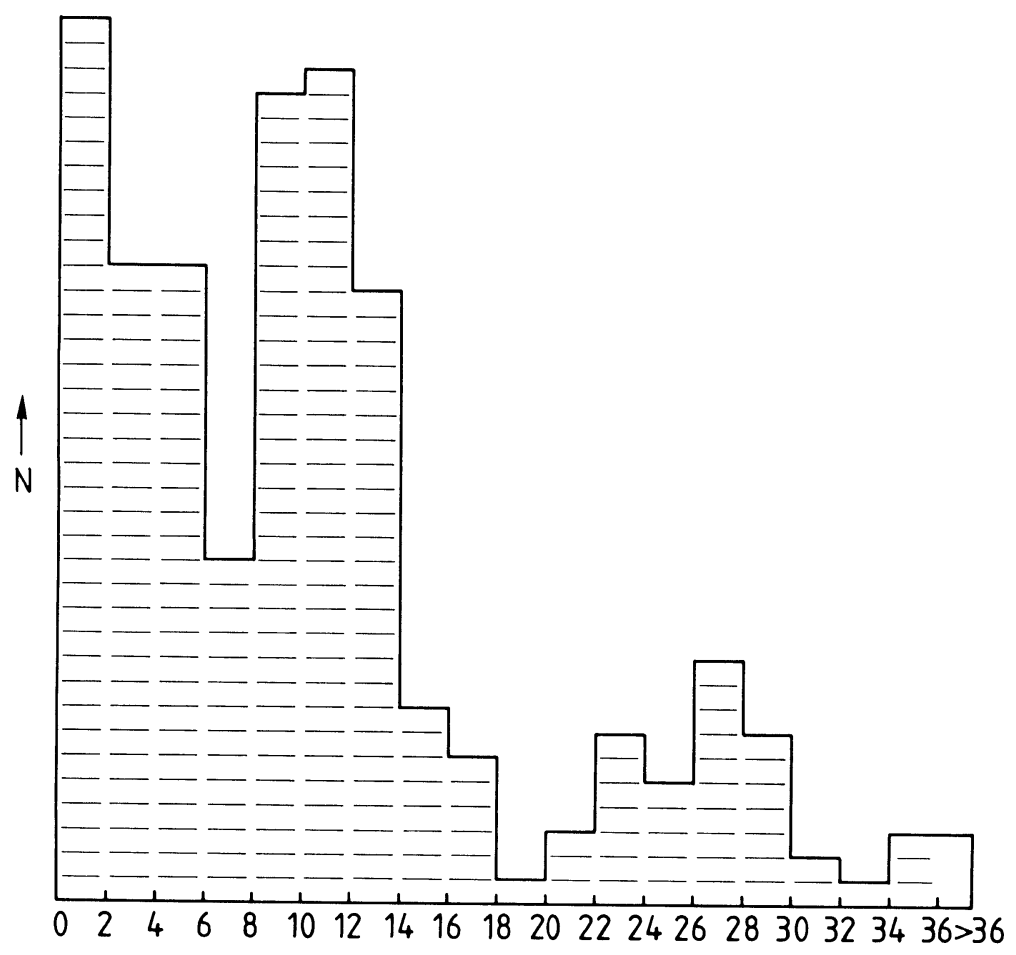

Fig 2. Distribution of ages of most of the measured archaeologic dates. The horizontal axis is in kilo-years. Each vertical unit corresponds to one date. 
as a special research project. Most other materials familiar to ${ }^{14} \mathrm{C}$ laboratories present no special points of interest, but mention should be made of the conservation treatment of samples, which have occasionally produced quite baffling dates.

\section{Usual Operation}

Our present ion source loads a wheel containing 20 targets. These generally consist of 3 standards prepared from the standard oxalic acid, 1 to 2 background, either laboratory chemicals or old wood, eg, and 0 to 2 targets prepared from known-age samples. The remainder are targets for dating. Usually these are in pairs, 1 sample giving 2 targets. This is fairly easy to do chemically; it provides some check on any possible target-related accelerator error, and above all, guards against charges of mislabelling of the targets. One day's operation is sufficient to achieve 1 to $1.5 \%$ statistics (depending on sample age) but since the dating rate limitation is at present with the target preparation, we usually run for 2 days. On average, 2 wheels are run a week (ie, 10 to 15 dates/week).

\section{Accuracy}

The main sources of error are contamination and fractionation during sample processing, non-reproducibility in beam transport between standard and dating targets, and counting statistics of the detected ${ }^{14} \mathrm{C}$ atoms. All three errors are included in the determination of known-age materials, and to an extent in laboratory intercomparisons (Burleigh, Leese \& Tite, 1986). Known-age materials cannot include background effects, which are considered below. A plot of the error in known-age samples dated mostly during the first few months of operation is shown in Figure 3. Many of

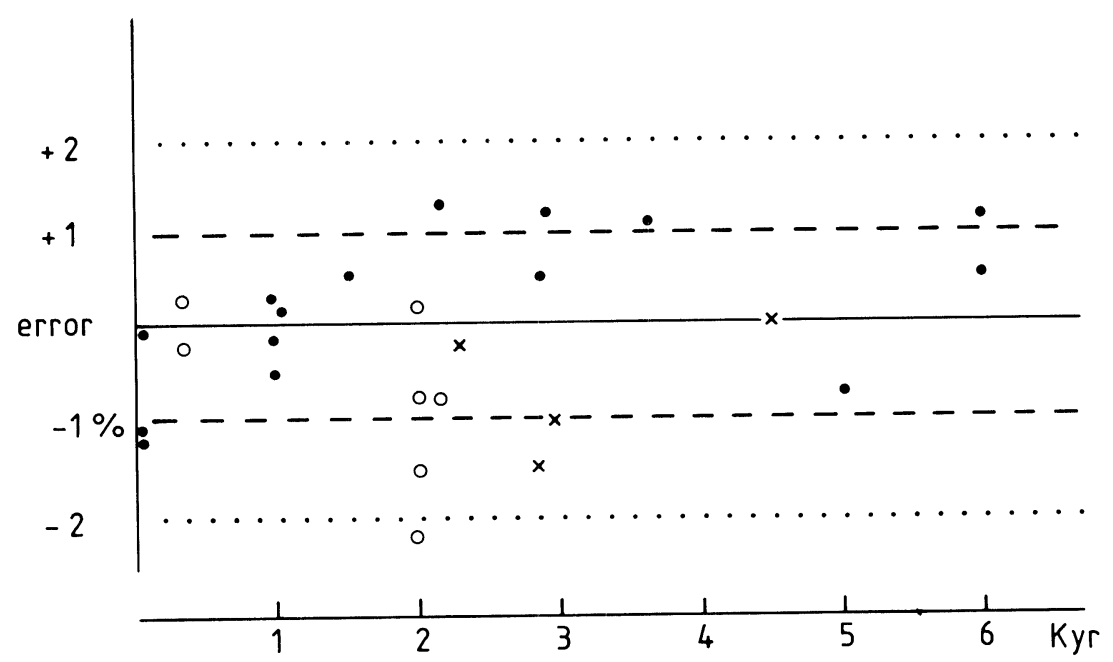

Fig 3. Measurements of known-age materials, with the actual error.

$\mathrm{O}=$ dendrochronologically-dated tree rings;

$x=$ seeds from archaeologically dated contexts;

= archaeologic material from Pompeii and the Mary Rose 
these were determined to a precision of better than $1 \%$, and it appears that the estimate of the error due to machine measurement has been overestimated. An estimate of the average machine error contribution during normal operation can be made by comparing the agreement between the three standards for each run. Most of the error comes from counting statistics, but a residual error of ca $0.5 \%$ ( 1 standard deviation) appears to be contributed by target/target variation. (This includes the chemical preparation of targets.) This error is consistent with our observations of stable isotope ratios, and is discussed further below. We have no direct evidence of errors arising from sample chemistry except where contamination by modern carbon becomes significant.

In general, the errors we quote are in the region of $1 \%$ for samples $<10,000 \mathrm{yr}$ old. Improvement to a consistent $0.5 \%$ is possible, but would take a great deal of time to verify, and should wait until a better understanding of the beam transport is available (see below).

\section{Background}

Virtually no improvement to the background has been made in the last year. We know that our standard target preparation method (Wand, Gillespie \& Hedges, 1984) is capable of producing backgrounds as low as $0.2 \%$ of the oxalic standard. We believe that sample pretreatment methods generally contribute $<0.5 \%$ to the background. However, the $\mathrm{Li} / \mathrm{C}_{2} \mathrm{H}_{2}$ method not infrequently produces alarmingly high backgrounds, so that the error in the estimate of the background is fairly high. (As a rule we consider it to be $0.5 \pm 0.3 \%$.) One major source is in the $\mathrm{Li}$ (or its handling). Since our long-term plans are to use a $\mathrm{CO}_{2}$-based source, and the $\mathrm{Li}$ problem is not easily solved, we have concentrated our efforts in the time range 0 to $30,000 \mathrm{yr}$.

TECHNICAL ASPECTS

\section{Chemistry: Pretreatment}

Routine methods for most sample materials have not changed from the previous reports (Gillespie \& Hedges, 1983; Gillespie, Hedges \& Wand, 1984). For bone, collagen (defined as the residue after treatment with $0.5 \mathrm{~N}$ $\mathrm{HCl}$ ) is hydrolyzed, the resulting amino acids purified by ion exchange and then dated as a mixture. As a rule we estimate the collagen content of a small sample first (by the TNBS method) before sampling what may be a valuable artifact. Most other materials follow conventional treatments. Three companion papers consider certain specific sample material in more detail. One type currently under investigation is the organic and inorganic content in shells and other carbonates.

\section{Chemistry: Target Preparation}

As a routine method the deposition of graphite upon a tantalum wire by the pyrolysis of $\mathrm{C}_{2} \mathrm{H}_{2}$ (Wand, Gillespie \& Hedges, 1984) has many attractions, including the specific design of ion source used and the accumulation of experience. Also the degree of fractionation seems highly reproducible, 
the targets handle and store well, and give large and stable beams. On the other hand, the yields rarely exceed $50 \%$, can be variable, and the method is subject to a variable amount of contamination by modern carbon. Further, the use of the $\mathrm{Li}$ reaction requires addition of water, and this is inconvenient for a routine vacuum line.

We have studied the occurrence of carbon by making residual gas analyses of the results of reacting only $\mathrm{Li}$ and $\mathrm{CuO}$ together, and also from the reaction of $\mathrm{Li}$ and $\mathrm{H}_{2} \mathrm{O}$. Addition of $\mathrm{Li}_{2} \mathrm{CO}_{3}$ to $\mathrm{Li}$ and $\mathrm{CuO}$ results in only a low yield of $\mathrm{CO}_{2}$, but addition of dil $\mathrm{HCl}$ enables the full yield of $\mathrm{CO}_{2}$ to be measured. In this way we can show that, in our method, most Li reactions contribute 0.2 to $0.4 \%$ carbon (presumably modern) to a $1 \mathrm{mg}$ sample. Different $\mathrm{Li}$ sources have not helped. In view of the difficulties with $\mathrm{Li}$, we have embarked upon an alternative method in which $\mathrm{CO}_{2}$ is reduced to $\mathrm{CH}_{4}$ by hydrogenation with a Ru catalyst. This has been carried out at high yield for $5 \mathrm{mg}$ samples. The resulting $\mathrm{CH}_{4}$ can best be trapped in molecular seive $10 \mathrm{~A}$ over liq N2. Cracking of $\mathrm{CH}_{4}$ to graphite must be performed at high pressure (500mbar). The overall yield seems comparable to the $\mathrm{Li} / \mathrm{C}_{2} \mathrm{H}_{2}$ route, and is compatible with our routine form of target. We have not been able to test targets in the accelerator because of a 4-month failure of the accelerator (see below), nor do we know about the likely background levels.

$\mathrm{CH}_{4}$ cracking is intended to be an interim method pending the satisfactory routine operation of the Middleton-type $\mathrm{CO}_{2}$ source. It would seem that oxidation of the sample by carefully degassed $\mathrm{CuO}$ is a satisfactory method of making $\mathrm{CO}_{2}$ (as measured by residual gas analysis). It may be of interest that an alternative method, oxidation by $\mathrm{CO}_{3} \mathrm{O}_{4}$, while convenient in many ways, gives an unacceptably high 'blank' $\mathrm{CO}_{2}$ level.

\section{Physics: Ion Source}

Reliable operation of the ion source is essential. The present source typically produces an average beam current of between 10 and $15 \mathrm{uA} \mathrm{C}^{-}$. Three major developments are under way:

1) The use of a replaceable 'cassette' containing cylindrical graphite targets on Ta wires. These can be rotated during operation so that sputtering is more uniform and the sample can be used more efficiently. Changing of samples does not require the vacuum to be lost. This source has been used on the test bench, but its development has been overtaken by the $\mathrm{CO}_{2}$ source.

2) A version of the Middleton-type $\mathrm{CO}_{2}$ source (Middleton, 1984) has been built, and a version, designed specifically for ${ }^{14} \mathrm{C}$ dating, and incorporating automatic changing of gas feeds and sputtering heads, is presently being fabricated. The $\mathrm{CO}_{2}$ source has been tested on the bench and can be relied upon to produce 15 to $20 \mathrm{uA}$ of $\mathrm{C}^{-}$from $\mathrm{CO}_{2}$. The consumption of $\mathrm{CO}_{2}$ for this current corresponds to an efficiency of ca $1 \%$. The background current (no $\mathrm{CO}_{2}$ flowing) is between 0.5 to $1 \mathrm{uA}$ and appears to be due, in part, to residual gas in the source (which incorporates many o-rings, etc) and, we suspect, to carbon ions focused back from the ionizer. We have no results on the background ${ }^{14} \mathrm{C}$ level to be expected from this source, 
except to point out that it acts as an extremely efficient residual gas detector and may have a significant memory.

3) Measurement of emittances from ion sources will be discussed in a detailed report. We are mainly interested in the nature and magnitude of the differences in beam distributions between different targets (or the same target at different times) in order to understand the underlying causes of isotopic transmission variability in the AMS system. Clearly, the more concentrated the emittance distribution, the less the problem in beam transport. The measured emittances for the back reflected source (routine source) and for the Middleton $\mathrm{CO}_{2}$ source are both variable, but of the order of $300 \mathrm{~mm}^{2} \mathrm{mrad}^{2} \mathrm{MeV}$.

A point of interest is the degree of spherical aberration resulting from using gridded lenses, which can significantly increase the effective emittance.

\section{Physics: Accelerator System}

The essentials of the accelerator system are unchanged (Hedges, 1984). The percentage of ${ }^{14} \mathrm{C}$ in the beam from an oxalic standard entering the detector is between 99.5 and 99.8. The transmission (conversion of $\mathrm{C}^{-}$ to detected $\mathrm{C}^{3+}$ ) is generally $22 \pm 2 \%$, corresponding to a total particle transmission of $70 \pm 10 \%$. The terminal voltage is stabilized in the long term from the position of the ${ }^{13} \mathrm{C}^{3+}$ pulsed beam within apparent limits of $\pm 50 \mathrm{~V}$ at $1.8 \mathrm{MV}$, although there is a mains ripple of ca $400 \mathrm{~V}(\mathrm{p}-\mathrm{p})$. Such stability is necessary for accuracies of better than 1 to $2 \%$ since the position of the ${ }^{14} \mathrm{C}$ beam at the final aperture (which rejects particles deflected by the velocity filter) is rather sensitive to the terminal voltage.

We are constructing a position measuring system for the ${ }^{12} \mathrm{C}^{-}$(pulsed beam) at the injector magnet, which will be used to stabilize the position of the injected beam. We observe that there are small but consistent differences in the directions of ion beams emitted from different targets, and believe that this is a contributing source of error.

We have started to make emittance measurements of the injected beam, and hope to compare beam characteristics with the isotopic ratio behavior of a given target. At present, we have shown that the emittance, at the $95 \%$ of total beam level, is ca 3 times smaller than the calculated system acceptance (2 dimensions only). This should give a higher and much flatter transmission through the accelerator than we observe. One cause may be the injection (gridded) lens which is filled to $50 \%$ by the beam, and which preliminary calculations suggest may be adding significant spherical aberration. There is much more work to be done on this subject.

A related question is the relative transmission of ${ }^{12} \mathrm{C}$ and ${ }^{13} \mathrm{C}$ ion beams. We have shown (Gillespie, Hedges \& Perry, 1984) that the measured ${ }^{13} \mathrm{C} /$ ${ }^{12} \mathrm{C}$ ratio is current dependent (rises by $1 \%$ per uA of $\mathrm{C}^{-}$beam), and that the effect is one of beam transmission. Calculations of the space charge of the injected beam (at $20 \mathrm{KeV}$ ), through our system (which contains three crossovers between source and accelerator tube) suggest that an increase in beam emittance with current (for ${ }^{12} \mathrm{C}$ ) of similar magnitude can be expected. It is not clear why, as mentioned above, the transmission should 
be so sensitive to changes in the beam emittance. But for accurate isotope ratios, where the ${ }^{13} \mathrm{C} /{ }^{12} \mathrm{C}$ ratio must be measured, the design of the injection system must take account of space charge effects.

\section{LOGISTICS, FUTURE DEVELOPMENTS, AND GENERAL EXPERIENCE}

\section{Dating Rate Per Year}

Over 200 samples have been dated in the last 6 months of operation, and the planned dating rate of $400 / \mathrm{yr}$ is realistic. This excludes standards, known-age, and background samples. The capacity of the accelerator system is many times higher, depending upon staff. To this end we are building a supervisory computer system which should make possible overnight running. The limitation is in the sample chemistry, of which about half the time is devoted to target preparation. A move to using a $\mathrm{CO}_{2}$ source would reduce the total sample chemistry time by about a third. We expect to increase the dating rate gradually to perhaps $800 / \mathrm{yr}$.

\section{Technical Support}

The chemistry laboratory is staffed by three technicians, the AMS by one. Most of the development has been carried out by post-doctoral research assistants in chemistry and physics, respectively. While not necessary for routine operation, their support can be invaluable at times of crisis.

The resources of time, money, and manpower required to operate the AMS system should not be underestimated. We recently suffered a downtime of four months following the repeated fracture of an accelerator tube due to buckling of the stripper housing.

At present, two graduate students are conducting research, and the contribution to the work of the laboratory by three previous graduate students should be acknowledged.

\section{Costs}

Although the calculation is somewhat arbitrary, the total cost of producing 400 dates/yr by the present system, including the initial capital cost over 15 years is ca $£ 400 /$ date. With maximal use of the accelerator time (1750 dates/yr), the cost would fall to $£ 200$. These figures do not include any element of research or development beyond essential improvements.

\section{THE DATING PROGRAM}

The Oxford Radiocarbon Accelerator unit was established to make major contributions to archaeology, primarily in the British Isles.

\section{Sample Selection and Administration}

Since the main advantage of dating milligram-size samples is greater selectivity, we have aimed to play a major role in sample selection, from choice of project to the context of the material submitted. The laboratory staff includes an archaeologist and a secretary/research assistant. Half of the dating time is made available by the laboratory to the Science and Engi- 
neering Research Council for dates requested by the UK academic community through the SERC Science-based Archaeology Committee. The archaeologist coordinates and manages such programs. At present, the demand presented by well-formulated projects is greater than the supply of dates, but not alarmingly so.

The other $50 \%$ of dating output involves other aspects of Quaternary studies, such as sediment dating. Apart from National Facility research through experimental dating, our projects often serve as links between areas dated for the National Facility. The experimental program also includes comparative work with other laboratories, and the dating of known-age materials.

\section{The Projects}

1) Late Palaeolithic. This period is ideal for AMS dating, especially in Europe where bone preservation is good. Dating can be done on actual artifacts, such as barbed bone points or harpoons, or faunal remains from sites where charcoal is scarce or difficult to purify. Work so far has concentrated on sites in Britain (eg, Gillespie et al, 1985; Jacobi et al, Accelerator mass spectrometry dating of Upper Palaeolithic finds with the Poulton elk as an example: ms in preparation) and northern France. Another project is dating the Klithi rock shelter in Greece and its environment.

2) Earlier Upper Palaeolithic. We have moved more cautiously here, but have worked on sequences such as Combe Saunière and Abri Pataud in southwest France.

3) Early Man in America. This is an in-house project on human skeletal remains some results of which have been published (Bada et al, 1984; Taylor et al, 1985; Gillespie et al, 1985). We have also worked on well-preserved organic remains from archaeologic sites such as Guitarrero Cave and Monte Verde.

4) Origins of Agriculture. These studies are made on seeds, grains, and faunal remains from Egypt, Syria, Jordan, and Israel.

5) Later Prehistory in Britain. We have only recently begun work on this period, since the production of results at $\pm 1 \%$ or better. Neolithic skeletal material from long barrows has been dated from West Kennet (Gillespie $e t$ $a l$, 1985). Bronze age metal work is now being studied, primarily on shaft traces in spearheads, and haft or sheath remains of other artifacts.

6) Known-Age Material. Samples from the last two millennia make up the major portion of our work, though many museum objects have been dated. The staples of our known-age dating are Pompeii (AD 79, ca $1950 \mathrm{BP}$ ) and the Mary Rose (AD 1545, ca $300 \mathrm{BP}$ ). Other research has been done on known-age grains (Gillespie et al, 1985).

7) Human Skeletal Remains. Specimens dated include some from the Mesolithic, others from the Late Pleistocene in southern Africa (Sealy \& van der Merwe, 1985) and Britain (eg, Sun Hole).

\section{SUMMARY}

Our experience can be summarized as follows:

1) Accelerator dating can entail quite different sampling considerations from conventional dating (eg, Gillespie \& Gowlett, 1983), and for 
results to be assessed in practice it is quite essential that results should be published rapidly.

2) At least 1 in 5 dates are contrary to expectation. In cases where doubtful context was the reason for dating (eg, an 'early' grain) this 'loss' is fully acceptable, but in other cases, it is crucial to avoid unnecessary failures, where, eg, an archaeologist's hopes were unrealistic. We have always stressed the need for careful selection of contexts, which is confirmed by our experience.

3) The ideal accelerator sample has a 'nested context,' $i e$, the sample is identifiable (eg, a grain, or a species of fauna); its presence provides its own context (eg, it is an artifact, or a reindeer bone indicating cold climate); and it is chosen from a reliable context where it can actually be used to date a layer.

\section{ACKNOWLEDGMENTS}

The Facility is largely supported by research grants from SERC. We gratefully acknowledge the help and skill of our technicians and research assistant, A D Bowles, J F Foreman, M J Humm, E Hendy, and A R T Stoker in the work of the laboratory.

\section{REFERENCES}

Bada, J L, Gillespie, R, Gowlett, J A J and Hedges, R E M, 1984, Accelerator mass spectrometry radiocarbon ages of amino acid extracts from Californian palaeoidian skeletons: Nature, v 312, p 442-444.

Batten, R J, Gillespie, R, Gowlett, J A J and Hedges, R E M, 1986, The AMS dating of separate fractions in archaeology, in Stuiver, $M$ and $\mathrm{Kra}, \mathrm{R} \mathrm{S}$, eds, Internatl ${ }^{14} \mathrm{C}$ conf, 12 th, Proc: Radiocarbon, this issue.

Burleigh, R, Leese, M and Tite, M S, 1986, An intercomparison of some AMS and small gas counter laboratories, in Stuiver, $\mathrm{M}$ and $\mathrm{Kra}, \mathrm{R} \mathrm{S}$, eds, Internatl ${ }^{14} \mathrm{C}$ conf, 12 th, Proc: Radiocarbon, this issue.

Fowler, A J, Gillespie, R and Hedges, R E M, 1986, Radiocarbon dating of sediments, in Stuiver, $\mathrm{M}$ and Kra, R S, eds, Internatl ${ }^{14} \mathrm{C}$ conf, 12 th, Proc: Radiocarbon, this issue.

Gillespie, R and Gowlett, J A J, 1983, Archaeological sampling for the new generation of radiocarbon techniques: Oxford Jour Archaeol, v 2, no. 3, p 379-382.

Gillespie, R, Gowlett, J A J, Hall, E T, Hedges, R E M and Perry, C, 1985, Radiocarbon dates from the Oxford AMS system: Archaeometry datelist 2: Archaeometry, v 27, no. 2, in press.

Gillespie, R and Hedges, R E M, 1983, Sample chemistry for the Oxford high energy mass spectrometer, in Stuiver, $\mathrm{M}$ and $\mathrm{Kra}, \mathrm{R} \mathrm{S}$, eds, Internatl ${ }^{14} \mathrm{C}$ conf, $11 \mathrm{th}$, Proc: Radiocarbon, $v 25$, no. 2 . in press.

Gillespie, R, Hedges, R E M and Humm, M J, 1986, Routine AMS dating of bone and shell protein, in Stuiver, $\mathrm{M}$ and $\mathrm{Kra}, \mathrm{R} \mathrm{S}$, eds, Internatl ${ }^{14} \mathrm{C}$ conf, 12 th, Proc: Radiocarbon, this issue.

Gillespie, R, Hedges, R E M and Perry, C, 1984, Status of the Oxford radiocarbon accelerator: Nuclear Instruments \& Methods, v B5, p 167-170.

Gillespie, R, Hedges, R E M and Wand, J O, 1984, Radiocarbon dating of bone by accelerator mass spectrometry: Jour Archaeol Sci, v 11, p 165-170.

Hedges, R E M, 1984, Radiocarbon and other radionuclide measurements by accelerator mass spectrometry: Nuclear Instruments \& Methods, v 220, p $211-216$.

Middleton, R, 1984, A review of ion sources for accelerator mass spectrometry: Nuclear Instruments \& Methods, v 233B,p 193-994.

Sealy, J and van der Merwe, N, 1985, Isotope assessment of Holocene human diets in the southwestern Cape, South Africa: Nature, v 315, p 138-140.

Taylor, R, Payen, L. A, Prior, C A, Slota, P J, Jr, Gillespie, R, Gowlett, J A J, Hedges, R E M, Jull, A J T, Zabel, T H, Donahue, D J and Berger, R, 1985, Major revisions in the Pleistocene age assignments for North American human skeletons by C-14 accelerator mass spectrometry: none older than 11,000 C-14 years BP: Am Antiquity, v 50, no. 1, p 136140 .

Wand, J O, Gillespie, R and Hedges, R E M, 1984, Sample preparation for accelerator-based radiocarbon dating: Jour Archaeol Sci, v 11, p 159-163. 